\title{
Effect of Water and Emulsifier on the Mechanical Properties of Cement Asphalt Mortar
}

\author{
Tri Ho Minh Le ${ }^{1}$, Dae-Wook Park ${ }^{1, *}$, and Jung-Woo Seo ${ }^{1}$ \\ ${ }^{1}$ Deptartment of Civil Engineering, Kunsan National University, 558 Daehak Ro, Jeonbuk, Korea
}

\begin{abstract}
The long-term operation of high-speed railway leads to remarkable issues in ballast mechanical degradation and track irregularity. Particularly, in mainline of rail structure, the required time for ballast layer maintenance is strictly short. To systematically cope with this problem, a comprehensive study was proposed to develop a new cement asphalt mortar (CAM) stabilized ballast method. This solution is expected to improve the ballast structural durability with fast application time. However, the engineer properties of CAM paste with different level of initial mixing water as well as the influencing mechanisms are not clearly understood. In this work, the effects of initial mixing water and emulsifier on the mechanical performance of CAM are mainly discussed. The characteristics of the mortar were determined by conducting the flowability test, mixing stability test, and unconfined compressive strength (UCS) test. The test results revealed that the initial mixing water plays an important role in both fresh and hardened stage of CAM, especially the demulsification process of asphalt emulsion. Meanwhile, the emulsifier imposed a critical effect on the strength development of CAM mixture.
\end{abstract}

\section{Introduction}

Due to long-term operation under high traffic and progressive maintenance process, the pressure transferred between ballast particles leads to the ballast degradation [1-2]. This critical fouling imposes a negative effect on the whole railway structure and causes geometry reduction. In facts, reports indicated that continuous rehabilitation and maintenance also trigger the deterioration of ballast [1-2]. Hence, an innovative and comprehensive strategy should be developed to resolve this issue [1-4].

Currently, some methods have been introduced to solve these problems and sustain the track comfort and safety levels. As regards the first, under sleeper pads or crumb rubber from tire waste was employed to partly reduce the vibration and track deteriorations [4]. However, the vertical settlement and bearing capacity have hindered this technique to be widely used. The use of geosynthetics is another method which has been studied for recent decades. In the research of Kennedy [5], a rigid compact type of polyurethane was injected into the ballast layer with the aim of reinforcing the structural integrity of the railway system. The author confirmed that both vertical and lateral deformation can be remarkably reduced. However, this solution is regarded as an impossible maintenance method due to its limitation in high initial cost and lack of productivity.

In railway system, the main advantage of nonballast slab track consists of long service life, high costeffectiveness and fast rehabilitation and maintenance [6]. This track technology gains more attention recently due to its combined merits of conventional concrete and ballasted track [7-10]. The concept was first introduced from the Japanese Railway Institute and it was widely developed by many countries, especially from Europe and China [10-11]. In this method, an interlayer made from CAM was injected between the concrete roadbed and track slab [8]. This layer will provide damping performance, improve riding smoothness, reduce stress to the below layer based on its pressure dissipation ability. Therefore, the whole railway structure durability can be enhanced. Based on recommendations by other research [7-12], the main components of CAM are asphalt emulsion, cement, sand, water, defoaming agent and some chemical admixtures. In the Shinkansen slab track in Japan, the low elastic modulus CAM is applied, meanwhile, the high elastic modulus CAM is preferred in Germany Bogl slab track. One of the main merits of CAM is its fast and simple application. Due to the selfleveling ability, CAM can be cast into narrow place between slab track and roadbed without compaction machine. CAM is shown to be very promising materials suitable for many applications, but this method must be conducted at the initial stage of construction [7-12]. The application of CAM in rehabilitation project show promising signals, however, there is lack of researches focussed on this solution.

Therefore, the proposed study aims to develop a new solution called Cement Asphalt Mortar Stabilized Ballast which not only reduce the global deformation, enhance the regularity and stability of ballast structure, but also produce an application with low cost. This concept introduces a new maintenance-free railway with ballast

\footnotetext{
$\bar{*}$ Corresponding author: dpark@kunsan.ac.kr
} 
covered by viscoelastic material (CAM). In this solution, CAM is sprayed directly above the ballast layer and the fresh materials will flow through the ballast structure based on its self-leveling behavior [3]. The stabilization of CAM will not only protect the fouled ballast but also provide a new stress adsorption system for the old granular layer. Within this method, the strict traffic closure time for railway maintenance can be also resolved due to its fast and simple application. Moreover, the components of this viscoelastic material (cement, asphalt emulsion, and sand) can be easily supplied by local companies with low cost. However, many engineer properties of the system with CAM and ballast layer must be comprehensively investigated in order to apply this method in large scale. This study mainly focusses on the initial stage of this railway maintenance solution with the aim of developing CAM mixture for stabilizing ballast layer. Further research will evaluate the performance CAM stabilized ballast under different load and temperature conditions.

In recent years, many studies have been conducted to investigate the engineer properties of CAM under different conditions from mix design modification to curing methods [7-12]. Zuo [13] indicates that the incorporation of sand with fineness modulus will improve the homogenous distribution of CAM particle. However, this fine aggregate may hinder the flowability of fresh paste due to its high adsorption. Regards to the viscoelasticity of CAM, this property can be significantly enhanced by increasing the asphalt/cement ratio [12]. The asphalt membrane layer will generate ductile behavior for the whole CAM structure. However, the increase in Asphalt Emulsion/Cement (AE/C) also imposes a negative effect since cement hydration products were poorly developed under high asphalt emulsion content and thereby, reducing the UCS of the material. Hence, the $\mathrm{AE} / \mathrm{C}$ ratio should be carefully adjusted to adapt both factors mentioned above. In addition to the early age of CAM, reports point out that the setting time of CAM was remarkably impacted by the $\mathrm{AE} / \mathrm{C}$ ratio. The initial and final setting of $\mathrm{CAM}$ paste can be reduced by increasing this ratio.

Recently, many CAM researches have been performed based on the constant water/cement ratio with fixed emulsifier content [7-9]. There has yet to be a clear investigation of the effect of initial mixing water to the engineer properties of CAM, especially in the demulsification process of asphalt emulsion. It is expected that the cement adsorption energy to asphalt droplets in $\mathrm{AE}$ can be influenced by initial mixing water to some extent. Also, the effect of emulsifier content in asphalt emulsion was not clearly evaluated. Therefore, it is of practical significance to also reveal the responsibility of the two components mentioned above on CAM performance. Hence, the main aim of this research is to systematically study the effect of initial mixing water and emulsifier to the engineer properties of CAM for railway maintenance. To cope with this purpose, CAM mixtures were fabricated with fives initial
$\mathrm{W} / \mathrm{C}$ ratios $(0.2,0.3,0.4,0.5,0.6)$ and three $\mathrm{E} / \mathrm{C}$ ratios $(0.01,0.02,0.03)$. The fresh behavior of CAM was figured out by conducting the flow cone test, mixing stability test. Then, the hardened stage of CAM was determined by employing the unconfined compressive strength test after 28days.

\section{Materials and Experiment Methods}

\subsection{Materials}

Table 1 and Table 2 exhibit the chemical and physical properties of Cement Portland Type II used in this study. Asphalt emulsion is an anionic type with properties shown in Table 3. Table 4 summaries the mix design based on cement weight. To identify the effect of initial mixing water to the mechanical property of CAM, the initial $\mathrm{W} / \mathrm{C}$ contents modified from 20 to $60 \%$ by mass of cement with an increment of $20 \%$. Meanwhile, to verify the effect of emulsifier, the admixture is increased from $0.5 \%$ to $2 \%$ with an increment of $0.5 \%$. This study also incorporates the use on quick hardening admixture (QA) at a level of $14 \%$ by mass of cement based on a trial test to achieve the fast strength development and eliminate bleeding phenomenon. In addition, the excessive air bubbles from asphalt emulsion are reduced by using $0.1 \%$ defoaming agent (by weight of cement) [10-12]. The initial adding water was mixed with $2 \%$ polycarboxylate superplasticizer based on the author team's experience.

Table 1. Chemical Composition of Cement by Percent.

\begin{tabular}{|c|c|c|c|c|c|c|c|}
\hline $\mathbf{S i O}_{2}$ & $\mathbf{A l}_{2} \mathbf{O}_{3}$ & $\mathbf{F e}_{2} \mathbf{O}_{3}$ & $\mathbf{C a O}$ & $\mathbf{M g O}$ & $\mathbf{S O}_{3}$ & $\mathbf{N a}_{2} \mathbf{O}_{3}$ & $\mathbf{f - C a o}$ \\
\hline 21.56 & 4.15 & 2.64 & 61.18 & 2.35 & 3.01 & 0.65 & 0.81 \\
\hline
\end{tabular}

Table 2. Physical Properties of Cement.

\begin{tabular}{|c|c|c|c|c|}
\hline $\begin{array}{c}\text { Fineness } \\
(\text { residue on } \\
\mathbf{8 0} \boldsymbol{\mu \mathbf { m } \text { sieve) }} \\
(\mathbf{\%})\end{array}$ & $\begin{array}{c}\text { Specific } \\
\text { surface } \\
\left(\mathbf{m}^{2} / \mathbf{k g}\right)\end{array}$ & $\begin{array}{c}\text { Initial } \\
\text { setting } \\
(\mathbf{m i n})\end{array}$ & $\begin{array}{c}\text { Final } \\
\text { setting } \\
(\mathbf{m i n})\end{array}$ & $\begin{array}{c}\mathbf{2 8} \text { day } \\
\text { compressive } \\
\text { strength } \\
(\mathbf{M P a})\end{array}$ \\
\hline 0.5 & 330 & 145 & 205 & 55 \\
\hline
\end{tabular}

\subsection{Mixing Process}

The wet mixing method is used in this study. First, dry materials (cement, QA, sand, defoaming agent) and water (with superplasticizer) are first mixed together for about 1 minute at a speed of $60 \mathrm{rpm}$, after which, asphalt emulsion was added to the wet mixture. After this period, the mixing time (5 mins) with rotation speed $(120 \mathrm{rpm})$ is applied to the batch. 
Table 3. Properties of Anionic Asphalt Emulsion.

\begin{tabular}{|c|c|c|c|c|c|}
\hline $\begin{array}{c}\text { Density } \\
\left(\mathbf{g}=\mathbf{c m}^{\mathbf{3}}\right)\end{array}$ & $\begin{array}{c}\text { Storage stability } \\
\mathbf{1} \mathbf{~ d a y}(\mathbf{\%})\end{array}$ & $\begin{array}{c}\text { Residue after } \\
\text { distillation } \mathbf{( \% )}\end{array}$ & $\begin{array}{c}\text { Residue on } \\
\mathbf{1 . 1 8} \mathbf{~ m m} \text { sieve (\%) }\end{array}$ & $\begin{array}{c}\text { Penetration depth at } \\
\left.\mathbf{2 5} \mathbf{5}^{\circ} \mathbf{( 0 . 1} \mathbf{~ m m}\right)\end{array}$ & $\begin{array}{c}\text { Solid } \\
\text { content } \mathbf{( \% )}\end{array}$ \\
\hline 1.02 & 0.3 & 50 & 0.01 & 70 & 50 \\
\hline
\end{tabular}

Table 4. Mixture proportion of CAM (based on cement weight).

\begin{tabular}{|c|c|c|c|c|c|c|c|c|}
\hline No & $\begin{array}{c}\text { Cement } \\
(\mathbf{C})\end{array}$ & $\begin{array}{c}\text { Quick Hardening } \\
\text { Admixture (QA) }\end{array}$ & $\begin{array}{c}\text { Asphalt } \\
\text { Emulsion (AE) }\end{array}$ & $\begin{array}{c}\text { Sand } \\
\text { (S) }\end{array}$ & $\begin{array}{c}\text { Added } \\
\text { Water (W) }\end{array}$ & $\begin{array}{c}\text { Superplasticizer } \\
\text { (SP) }\end{array}$ & $\begin{array}{c}\text { Defoaming } \\
\text { Agent (D) }\end{array}$ & $\begin{array}{c}\text { Added } \\
\text { Emulsifier }\end{array}$ \\
\hline A1 & $100 \%$ & $14 \%$ & $75 \%$ & $50 \%$ & $20 \%$ & $2 \%$ & $0.1 \%$ & $0 \%$ \\
\hline A2 & $100 \%$ & $14 \%$ & $75 \%$ & $50 \%$ & $30 \%$ & $2 \%$ & $0.1 \%$ & $0 \%$ \\
\hline A3 & $100 \%$ & $14 \%$ & $75 \%$ & $50 \%$ & $40 \%$ & $2 \%$ & $0.1 \%$ & $0 \%$ \\
\hline A4 & $100 \%$ & $14 \%$ & $75 \%$ & $50 \%$ & $50 \%$ & $2 \%$ & $0.1 \%$ & $0 \%$ \\
\hline A5 & $100 \%$ & $14 \%$ & $75 \%$ & $50 \%$ & $60 \%$ & $2 \%$ & $0.1 \%$ & $0 \%$ \\
\hline A6 & $100 \%$ & $14 \%$ & $75 \%$ & $50 \%$ & $40 \%$ & $2 \%$ & $0.1 \%$ & $1 \%$ \\
\hline A7 & $100 \%$ & $14 \%$ & $75 \%$ & $50 \%$ & $40 \%$ & $2 \%$ & $0.1 \%$ & $2 \%$ \\
\hline A8 & $100 \%$ & $14 \%$ & $75 \%$ & $50 \%$ & $40 \%$ & $2 \%$ & $0.1 \%$ & $3 \%$ \\
\hline A9 & $100 \%$ & $14 \%$ & $100 \%$ & $50 \%$ & $20 \%$ & $2 \%$ & $0.1 \%$ & $0 \%$ \\
\hline A10 & $100 \%$ & $14 \%$ & $125 \%$ & $50 \%$ & $20 \%$ & $2 \%$ & $0.1 \%$ & $0 \%$ \\
\hline
\end{tabular}

\subsection{The flowability test}

In this research, the flowability of CAM paste is figured out by conducting a flow cone test based on Korean Standard KSF2432 [14]. In this test, a fresh CAM mixture of $400 \mathrm{ml}$ was cast into the steel cone with closed end nozzle. The time for the whole mixture to fully flow out of the funnel is recorded and is then considered as the flow time.

\subsection{The mixing stability test}

The mixing stability test of CAM was performed based on the Korean standard, KS M2203 [15]. First, 50\% solid content asphalt emulsion was prepared by mixing with deionized water. Then, $50 \mathrm{~g}$ of this asphalt emulsion was mix with $50 \mathrm{~g}$ of cement at a shear rate of $120 \mathrm{rpm}$ for 2 mins. After that, the mix with additional $150 \mathrm{ml}$ water was applied a stirring speed of $60 \mathrm{rpm}$ for $3 \mathrm{mins}$. Finally, the residue of the mixture was filtered by using a $1.18 \mathrm{~mm}$ sieve. The residues retained on the sieve were oven dried and measured (Fig.1a). The mixing stability status of the mixture was calculated by using Eq. (1).

$$
\boldsymbol{P}_{r}=\frac{\boldsymbol{m}}{\boldsymbol{m}_{\mathbf{1}}+\boldsymbol{m}_{2}} * 100 \%
$$

where

- $\mathrm{P}_{\mathrm{r}}$ is the residue content;

- $\mathrm{m}$ is the weight of residues $(\mathrm{g})$;

- $\mathrm{m}_{1}$ and $\mathrm{m}_{2}$ are the weight of cement and asphalt (g), respectively.
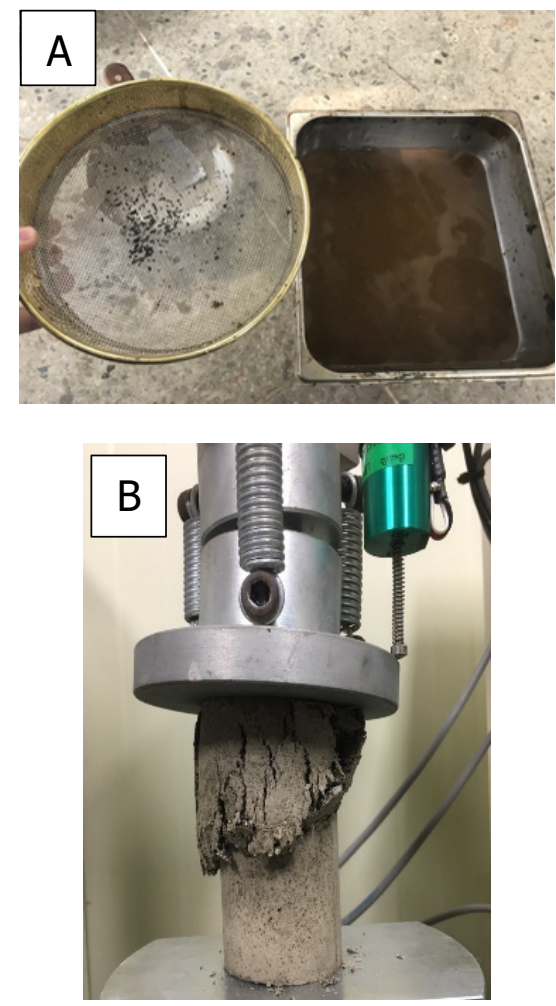

Fig. 1. Actual picture conducting mixing stability test (a), unconfined compressive strength test (b).

\subsection{The unconfined compressive strength test}

The UCS test was applied on samples at $2 \mathrm{hrs}$ and 28 days strength. A $\Phi 50 \times 100 \mathrm{~mm}$ laminated paper mold was used to fabricate test sample. The 28 days strength samples were demolded after $24 \mathrm{hrs}$ and then cured at $95 \%$ relative humidity at $20^{\circ} \mathrm{C}$. The loading rate was controlled at $1 \mathrm{~mm} / \mathrm{min}$ by using the universal testing machine and 3 replicates were employed for the average value (Figure 1b). 


\section{Discussions}

\subsection{Flowability test}

Figure 2 illustrates the flowability test results of CAM with different $\mathrm{W} / \mathrm{C}$ ratios. As regards the first, mixtures with higher $\mathrm{W} / \mathrm{C}$ had a faster time to flow out of the flow cone nozzle. For examples, mix A5 with $60 \% \mathrm{~W}$ content required only 15 seconds to finish the flow cone test, meanwhile, the required time for mix A 1 with $20 \% \mathrm{~W}$ is more than two times ( 35 seconds). It can be found from the test results that the reduction in W/C remarkably prolonged the flow time with agglomeration phenomenon of CAM particles at the nozzle of steel cone apparatus. The establishment of bigger CAM particles size was easily witnessed when the W/C was lower than $40 \%$.

Theoretically, the increase in $\mathrm{AE} / \mathrm{C}$ ratio leads to the increase in final water content since nearly $50 \%$ of the asphalt emulsion is water. However, the test results verified that the increase in $\mathrm{W} / \mathrm{C}$ by using higher $\mathrm{AE} / \mathrm{C}$ ratio did not show a clear effect on the flowability test results. As can be seen from Fig. 2, although the AE was increased to $125 \%$, the flow time of mix A10 was shortened to only 2 s compared to mix A1. Hence, it can be concluded that the initial mixing water plays an important role in controlling the flowability of CAM. Based on mix A6 to A8 results, the differences in flow time of CAM mixtures with emulsifier modified from 1 to $3 \%$ can be neglected.

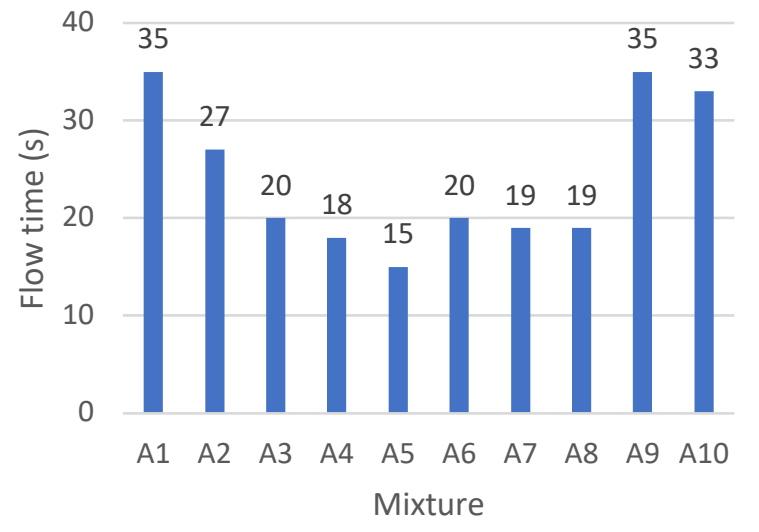

Fig. 2. Flow cone test results.

\subsection{Mixing stability test}

The mixing stability of CAM with varied $\mathrm{W} / \mathrm{C}$ and emulsifier ratios was presented in Fig. 3. The higher the $\mathrm{W} / \mathrm{C}$, the better the homogenous distribution of CAM particle size was obtained. It should be noted that the particle size of CAM mixtures with high water content was much finer than mixtures with lower initial water. As seen from Fig. 3, the residue content of CAM mixtures with low water content (A1, A2) was significantly higher than mix with high initial water value (A3 to A8). For examples, the residue contents of mix A1, A2, and $\mathrm{A} 3$ were 5.6, 2.8 and $0.1 \%$ respectively. In mixture with low initial mixing water, the test results revealed that there is a higher chance of formation of bigger particle size and inhomogeneous particle distribution. This may be due to the adsorption energy of cement particle to the asphalt droplets in asphalt emulsion. If the cement particle adsorption energy was not well mitigated, the demulsification of asphalt emulsion can be accelerated at very fast rate or triggered immediately [10-12]. In mixture with high initial water content, this phenomenon can be resolved since water droplets will cover cement particles and they behave as interlayer that protects the asphalt droplets from fast demulsification process. Therefore, the test results agree with the findings from the flowability test and explain why mixture with high initial water achieve ideal flowability results.

In terms of the effect of water from asphalt emulsion, the effect of the increase in $\mathrm{AE} / \mathrm{C}$ ratio to the mixing stability is neglectable (mix A9, A10). Regards to those mixtures with different added emulsifier content, the test results show that the utilizing of this admixture provides a very slight improvement in the rheology of CAM.

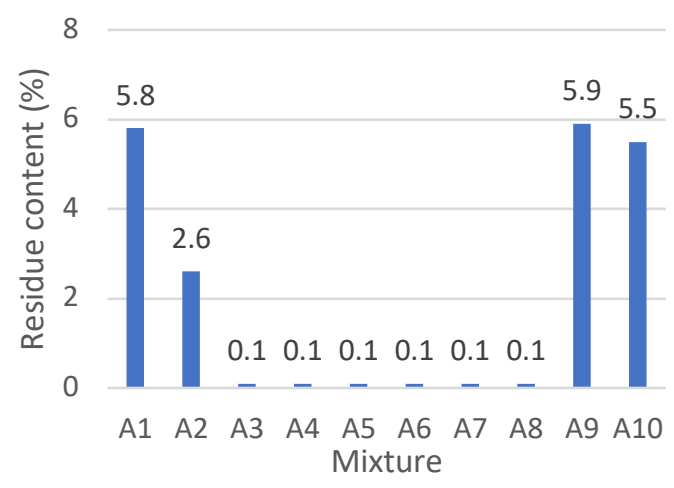

Fig. 3. Mixing stability test results.

\subsection{Unconfined compressive strength test}

The UCS test results of CAM mixture were exhibited in Fig. 4. Both 2hrs strength (Fig 4a) and 28days strength (Fig.4b) values show the same trend in strength developing of CAM mixture as presented following. In those mixtures with low $\mathrm{W} / \mathrm{C}$ ratios, due to the bad uniformity of CAM particle size and the fast demulsification process of asphalt emulsion, the compressive strength results of those mixtures are considerably low. It can be explained by the poor bonding between cement hydration product and asphalt membrane [10-12]. The fast coalescence of asphalt droplets also led to the critical drop in strength development [10-12]. Moreover, the required water for the full hydration of cement may be not provided enough. Meanwhile, mixtures with very high initial mixing water content of about $60 \%$ also suffered from a reduction in strength gain. The excessive use of water will prolong the hardening time and keep the cement hydration productivity at a slow rate. Moreover, because of the water evaporation, the high air void system in mixture with higher water content may also contribute to the strength reduction. Therefore, the initial W/C not 
only impact the fresh stage of CAM but also play an important role in the strength development of CAM material.

In addition to the role of emulsifier content, although emulsifier did not have a clear effect on CAM properties at the fresh stage, this admixture imposed a negative effect on the compressive strength development. For examples, when the added emulsifier content was increased from 1 to $3 \%$, the UCS of mix A6, A7, and A8 are $3.5,3.3$ and $3.2 \mathrm{MPa}$ respectively. The high emulsifier in CAM mixture may prolong the workable time as well as the hardening time of mixture to some extent and thereby, lowering the strength gain of the mixture after 28 days.

In terms of asphalt emulsion effect, the increase in $\mathrm{AE} / \mathrm{C}$ ratios of mix $\mathrm{A} 1$ illustrates a noticeable reduction in strength (mix A9, A10). This may be due to the high asphalt content in mixture leads to the slow development of cement hydration product. It is predicted that the asphalt membrane may cover the cement particle and delay the interaction between cement and water. Also, the asphalt content may mainly support the viscoelasticity of CAM material. Meanwhile, cement hydration product is responsible for creating stress bearing skeleton for the whole CAM structure.

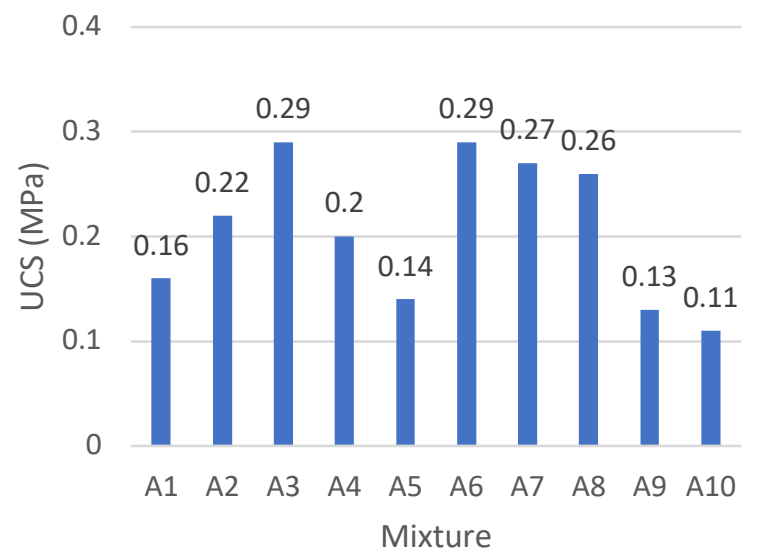

(a)

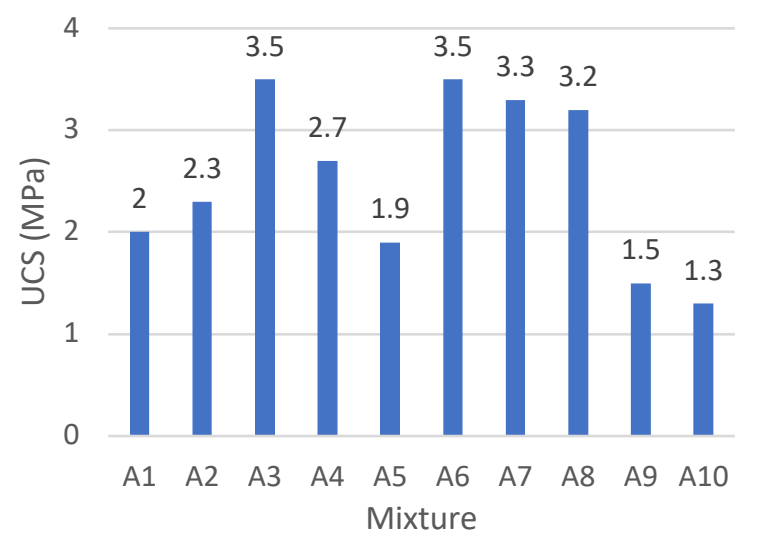

(b)

Fig. 4. Unconfined compressive strength test results at $2 \mathrm{hrs}$ (a) and 28days (b).

\section{Conclusions}

This study presented the analysis of the potential of CAM, as a stabilization method for fouled ballast. For this purpose, this manuscript covers a part of this comprehensive study process by conducting laboratory tests on the rheology and hardened properties of CAM under different initial water and emulsifier conditions.

The obtained results led to the following conclusions:

- The test results show that the acceptable flowability of CAM mixture can be acquired by using higher initial adding water. This is due to the adsorption ability of cement particle was partly reduced by water and its effect to asphalt droplet in asphalt emulsion was mitigated. The test results verified that the effect of added emulsifier on the demulsification process can be neglected.

- The adsorption rate of cement may be reduced by adding more water, which significantly improves the mixing stability of asphalt emulsion in the fresh mixture. During the mixing process, the demulsification process can be delayed and the durability of asphalt droplets in AE can be enhanced in mixture with high initial water content. The test results revealed that mixtures with high water content had a minimal sign of residue content retained on a $1.18 \mathrm{~mm}$ sieve.

- Due to better uniformity and finer size of CAM particles, the compressive strength of mixture with optimum water is higher than mixture with lower initial mixing water.

- It should be mentioned that excessive use of water also leads to the huge drop in strength gain of CAM mixture. When the $\mathrm{W} / \mathrm{C}$ ratio was set at higher than 0.6 , the excessing water diffuses out from coalesced asphalt droplets may cause the delaying in the hydration process of cement, which imposes a negative effect on the hardening ability of mortar.

This research was supported by a grant (19RDRP-B076564-05) from Regional Development Research Program funded by Ministry of Land, Infrastructure and Transport of Korean governmentrean Government

\section{References}

1. Selig, E.T., Waters, J.M. (1994). Track. Geotechnology and Substructure Management, T. Telford.

2. Pires, J., Dumont, A.G. (2015). Railway ballast degradation, 15th Swiss Transport Research Conference.

3. D'Angelo, G., Thom, N., Presti, D.L. (2016). Bitumen stabilized ballast: A potential solution for railway track-bed. Construction and Building Materials. 125, 118-126. 
4. Brown, S.F., Kwan, J., Thom, N.H. (2007). Identifying the key parameters that influence geogrid reinforcement of railway ballast, Geotext. Geomembr. 25(6), 326-335.

5. Kennedy, J.H., Woodward, P.K., Medero, G.M., McKinney J. (2009). Full-scale cyclic geopavement \& railway accelerated fatigue testing, 10th International Railway Engineering Conference, (2009).

6. Lee, S.H., Lee, J.W., Park, D.W., Vo, H.V. (2014). Evaluation of asphalt concrete mixture for railway track. Construction and Building Material. 73, 1318.

7. Zhangshen, L., Xiaofeng, W., Zhenjun, W., Bo, Y., Yaogang, T., Rui, H. (2017). Damping characteristics of cement asphalt emulsion mortars. Construction and Building Materials. 173, 201-208.

8. Song, H., Do, J., Soh, Y. (2006). Feasibility study of asphalt-modified mortars using asphalt emulsion, Construction and Building Materials. 20(5), 332337.

9. Quiang, W., Yang, J., Kong, X. Strength Mechanism of Cement-Asphalt Mortar. Journal of Materials in Civil Engineering 201.

10. Ouyang, J., Hu, L., Li, H., Han, B. (2018). Effect of cement on the demulsifying behavior of overstabilized asphalt emulsion during mixing. Construction and Building Materials. 177, 252-260.

11. Ouyang, J., Tan, Y., Li, H. (2014). Factors influencing rheological properties of fresh cement asphalt emulsion paste. Construction and Building Materials. 68, 611-617.

12. Ouyang, J., Zhao, J., and Tan, Y. (2018). Modeling Mechanical Properties of Cement Asphalt Emulsion Mortar with Different Asphalt to Cement Ratios and Temperatures. Journal of Materials in Civil Engineering, 30.

13. Zuo, J.Q., Jiang, Q.B., and Cai, B.F. (2005). Experimental study on emulsified asphalt for CA mortar used in slab track. Rail. Constr. Technol., 2(2), 68-70.

14. KS F 2432: Testing Method for Consistency of Mortar Grouting

15. KS M 2203: Emulsified Asphalt 